\title{
The Concept of Autism Spectrum Disorder-A Review Literature
}

\author{
Agyekum HA* \\ Departure of Social Work, Ghana
}

*Corresponding author: Agyekum HA, Departure of Social Work, Ghana

Received Date: October 25, 2018

Published Date: November 13, 2018

\begin{abstract}
On the assumption that enough work has been done on autism spectrum; this study reviews the exiting literature on the topic. The study first sorted out what existing literature is saying on the topic and what different researchers have said about the disorder. The paper then reviews this large body of research and, in so doing, explores a host of studies in the field. The broad knowledge of ideas was set along side works that has been done in Ghana to ascertain if laid down facts holds in Ghana. The analyses showed what the disorder is, the causes, symptoms and brought it down to look at the disorder in Ghana.
\end{abstract}

\section{Introduction}

With the discovery of autism spectrum disorder a lot of work has been done to discover exactly what the disorder is about. Over the years, statistics on children with Autism Spectrum Disorder has seen an increase all over the world. This has led to a number of researches done to know the exact cause as well as cure that can be provided to people with the disorder. Autism Spectrum Disorder is a very common developmental disability which occurs in 1 out of 110 children over the world [1]. The term has been defined by Boltes [2] as "a neurodevelopmental disorder persisting deficits in social interaction across multiple contexts, alongside restricted, repetitive patterns, interests, or activities as manifested by at least two prototypically inflexible behaviors." Due to its similarity with other disorders like Asperger Syndrome, Atypical Autism and Disintegrative Disorder, the term was changed from Autism to Autism Spectrum Disorder [3]. Autism Spectrum Disorder is a condition that is gradually increasing in every part of the world. It only behooves everyone to find a way of inculcating or integrating all these people into the larger society, it is towards this course that Ochs \& Solomon [4] calls for an autistic sociality. In their study, they call for a society that will understand and enhance the social engagement of children with this disorder. Persons with autism need to be viewed not only as individuals in relation to other individuals, but as members of social groups and communities who act, and display both social competencies and difficulties, in relation to socially and culturally ordered expectations of behavior [5]. Most of the previous studies have been generalized, however there stand a question of if the knowledge obtained have been made known to the world and also if the findings can be generalized. Most studies reviewed in this work were done in countries other than Ghana, the study explores and analyses the findings of the studies in the Ghanaian context. The focus of this work is to look at the findings in previous studies compile the studies and bring out the conception Ghanaians have about the disorder.

\section{Understanding Developmental Disorders (Autism)}

Developmental disability has been defined by the Centers for Disease Control and Prevention as "a group of conditions due to impairment in physical, learning, language, or behavioral areas." It has been estimated that, one in every six children in the United States has a developmental disability, with it having a greater chance of occurring in males than in females [6]. David Skuse [7] is of the view that girls are protected by the X chromosome they inherit from their fathers making them less likely to have developmental disorders as compared to boys. These developmental conditions begin during the developmental period and usually last throughout a person's lifetime [8]. Most developmental disorders are diagnosed under the age of 9. It is easily noticed when there is a communication disorder, where children are having difficulties speaking by the school going age [9]. Though these are all signs to look out for in children when they are growing, Ghanaian parents usually attribute these as their children being slow and lazy. They hardly see these symptoms as conditions that need medical attention, and therefore resort to caning and doing other disciplinary actions to get them to change. 


\section{Autism Spectrum Disorder}

Autism Spectrum Disorder is a very common developmental disability and one that is usually not noticed early in Ghana. Due to autism's similarity to other developmental disorders, Autism Spectrum Disorder has been used to classify all disorders that have a similarity to autism [10]. Autism is a developmental disorder characterized by difficulties with social interaction, social communication and an unusually restricted range of behaviors and interests [11]. Autism symptoms can be seen by parents or daycare givers, upon the realization that the child is growing differently from his peers [1]. It is a highly delved into topic, hence the numerous changes in the understanding of the disorder [5]. Wolff hints that, since its discovery, there has been a lot of journals and publications on it, which were mostly funded by Parent's Associations. This illustrates that parents are always eager to know more about their children with autism and what they can do to help them. The numerous works done by researchers over the years have brought about frequent changes in the concept and definition of the term, which recently ended with it being called Autism Spectrum Disorder [5]. Over the years, the concept of autism has broadened to include Asperger Syndrome and Pervasive Development Disorder-Not Otherwise Specified (PDD-NOS), hence the umbrella term Autism Spectrum Disorder [12,13].

Sole-Smith [13] asserts that autism was first used in 1908, but Wolff's work in 2003, said that the term had been discovered 60 years ago, referring to 1943 , as such, it can be said to be a known word from the early 1900s. The Morbidity and Mortality Weekly Report (2014) reports that Autism Spectrum Disorder is recorded all over the world, irrespective of gender or race, with differences occurring only in the level of awareness of the disorder. This shows that autism deserves all the attention given since it is prevalent.

Simmons and colleagues [10] have defined Autism spectrum disorders as "developmental disorders which are thought primarily to affect social functioning." Due to the adoption of Autistic Spectrum Disorder, autism has been made simpler to understand and also identify, as there are now general symptoms that one can observe in children, whereas, in times past, there would have been the need to distinguish autism from the other disorders [14].

\section{Causes of Autism}

Some time ago, autism was believed to have resulted from the mother's hostility towards the child during pregnancy [14] and the administration of child vaccines to younger children in hospitals (where every baby is required to take some vaccinations to prevent them from illness) caused the disorder to grow [1]. However, the latter was disputed by Taylor and colleagues in their study in 2002 [15]. In their study they realized that autism was not caused or triggered by vaccination, especially Measles, Mumps, and Rubella (MMR) vaccination. Even though much information is now available on the disorder, the exact cause is not known $[1,14]$. It has however been suggested to be caused by genetic or environmental factors [14]. Shen Y et al. [16] have emphasized that, there is a strong genetic contribution to Autism Spectrum Disorder. Though the genetic cause of autism is not readily proved, Folstein \& Rosen-Sheidley [17] have stated that regions on chromosomes 2, 7 , and 13 may contain one or more susceptibility genes but actual susceptibility genes have not yet been identified. Those who are for the environmental factors causing the disorder base their argument on the increasing figures in areas with environmental stressors, such as pollution, poor diet or lifestyle [10]. It is however likely that both environmental and genetic factors could be the influential cause of autism [18].

\section{Symptoms of Autism}

The major symptoms that autistic children show is a typical social behavior; disrupted verbal and non-verbal communication; and unusual patterns of highly restricted interests and repetitive behaviors [12].

Atypical social behavior refers to not behaving in accordance with the acceptable ways of the society. Autistic children do not follow the usual way of communication in children. They express differences in the way they behave, with some individuals displaying an aloof style of social interaction, and others actively seeking personal interactions, albeit in a socially odd manner [3]. Frith \& Happé [19] in their study outlined the activities of an autistic child, stating that, "he did not look at others' faces or point out things of interest he would take an adult's hand and move it towards an object he wanted, as if the hand were a tool." They express behaviors such as being locked into an egocentric stance, being unable to make friends, tending to interpret utterances literally and failing to notice when others are mocking them or taking advantage of them [19]. Autistic children hardly read meanings into what other people say [20]. They however do not have a problem making moral judgments, though they have a rather rigid criterion for what is moral [21].

Children with Autistic Spectrum Disorder show symptoms of delayed speech or not being able to communicate at all [12]. Noncommunication differs with the children, with some being able to communicate a few words and others not being able to talk at all. Non-communication is one major symptom of Autistic Spectrum Disorder. A research conducted by McEvoy et al. [20] showed that Autistic children exhibited significantly more perseverative responses on a test of executive function when compared to both children without any form of disability and those with other forms of disability. They went on to further state that, even those who could engage in some form of social interaction could still not communicate with their peers. These children are said to have problems with their social interaction and communication skills because they do not have a theory of mind [22].

Before the age of two, it is expected that, children will be engaging in various activities that will enable them to realize the things they like to do and what they do not like to do. However, with children with Autistic Spectrum Disorder, they engage in the same behavior they learn over and over again [7], and get upset when they are being asked to stop, or their normal pattern of life is distracted [1]. Richler et al. [4] stated in their research that there is the presence of a repetitive sensorimotor (RSM) factor and an insistence on sameness (IS) factor in children with Autistic Spectrum Disorder which make them behave in a repetitive and restricted way.

\section{Sociocultural Perspectives on Autistic Children}

The sociocultural perspective of people refers to the people's way of viewing circumstances surrounding them, as well as how 
they interpret their circumstance. Ginsburg \& Rapp [23] are of the view that disability is not simply lodged in the body but created by the social and material conditions that "dis-able" the full participation of a variety of minds and bodies. They explain that, an individual is disabled because the environment in which he finds himself does not have the favorable conditions needed for him to life a fulfilling and comfortable life. Thus, if societies create an enabling environment, there will be no disables in the world. An instance is the inclusion of wheelchair users in public life, which has led to an aspect of universal design that is fundamental to a fully democratic built environment [24].

\section{Autism in Ghana}

In Ghana, there is insufficient data on autism and no separate category for it [25]. This in itself shows the kind of perception Ghanaians have about autism. Anthony [25] reports that the perceived causes of autism in Ghana are complex and vary widely over time and circumstances, though most of them are not familiar with the term. The cause of autism has mainly been linked to either biomedical perspectives or spiritual forces or both [25]. For those who attribute autism to biomedical causes, they perceive it to be caused by severe illness or high fever or seizures (convulsion), which is usually blamed on the mother of the autistic child [25]. They perceive autism to come about when the mother of the autistic child falls sick or gets involved in an accident during pregnancy, a failed abortion, the aftermath of getting pregnant for another man aside her husband and lack of maternal effort during pregnancy. Anthony [25] further asserts that individuals who believe in the spiritual realm attribute autism to demons with spiritual powers or through retribution from higher powers. He explains that people often associate the main cause to be retribution for transgressions committed by someone close to the family of the autistic child. Anthony again illustrates that there are instances where someone, especially a witch or an individual with spiritual powers is jealous of the mother, and as such, intentionally inflicts the illness on the child.

Nukunya [26] corroborates Anthony's findings, when he observed that Ghanaians have a spiritual worldview and as such, parents believe that autism is a spiritual occurrence. Some others suggest that parents usually rely on their delivery doctors to find out if something went wrong during the delivering process [27]. Some Ghanaian parents, even though, they sent their children to the Child Development Center which uses a biomedical model, refused to treat their children's problems with medicine but rather relied on religious approaches and other behavioral interventions [28]. Bakare et al. [29] have indicated that in the sub-Sahara Africa, the information provided by health care workers to parents whose children have autism are sometimes inadequate, misguided and misleading.

The belief we have on the cause of an illness defines the cure we will be seeking for it [30]. Against this backdrop of some Ghanaians believing that autism is either caused by the biomedical [31] or spiritual factors [30], they could easily determine what kind of cure to seek for their autistic child or children. Anthony [25] noted that, the society has reservations with regards to their interactions with autistic children. However, the family of an autistic child often supports the mother in childcare duties. Manu [31] observes that mothers with autistic children required more assistance from their husbands than mothers without autistic children [32].

\section{Conclusion}

The number of parents bringing forth children with Autism Spectrum Disorder is on an increase worldwide, to which Ghana is not an exception [14]. Taking care of children with autism comes with a lot of challenges, it is against this that this study seeks to explore the works that have been done about others, serving as a compilation and bringing out the perspectives that Ghanaians have on the topic. A formal study should be done on exactly what Ghanaians know about the disorder.

\section{Acknowledgment}

I am grateful to God for making this study a success. I am immensely grateful to my supervisor Dr. Kingsley Saa-Touh Mort, my family and friends and Dr. Akosua Darkwah of University of Ghana, Sociology Department.

\section{Conflict of Interest}

No conflict of interest.

\section{References}

1. Speaks A (2011) What is autism?

2. Bolte S (2014) “Is autism curable?" Developmental Medicine \& Child Neurology 56(10): 927-931.

3. Volkmar FR, Cohen DJ, Bregman JD, Hooks MY, Stevenson JM (1989) An examination of social typologies in autism. J Am Acad Child Adolesc Psychiatry 28(1): 82-86.

4. Richler J, Bishop SL, Kleinke JR, Lord C (2007) Restricted and repetitive behaviors in young children with Autism Spectrum Disorders. J Autism Dev Disord 37(1): 73-85.

5. Wolff S (2004) The history of autism. Eur Child Adolesc Psychiatry 13(4): 201-208.

6. Boyle CA, Boulet S, Schieve LA, Cohen RA, et al. (2011). Trends in the prevalence of developmental disabilities in US children, 1997-2008. Pediatrics 127(6): 1034-1042.

7. Williams PG, Dalrymple N, Neal J (2000) Eating habits of children with autism. Pediatr Nurs 26(3): 259.

8. Holm VA (1989) Developmental Disabilities: Delivery of Medical Care for Children and Adults. JAMA 262(20): 2935-2936.

9. Sawin KJ, Rauen K, Bartelt T, Wilson A, O'Connor RC, et al. (2015) Transitioning adolescents and young adults with spina bifida to adult healthcare: initial findings from a Model Program. Rehabil Nurs 40(1): $3-11$.

10. Simmons DR, Robertson AE, McKay LS, Toal E, McAleer P, et al. (2009) Vision in Autism Spectrum Disorders. Vision research 49(22): 27052739.

11. Frith U (2003) Autism: Explaining the enigma. Blackwell science.

12. Geschwind DH, Levitt P (2007) Autism Spectrum Disorders: developmental disconnection syndromes. Current opinion in neurobiology 17(1): 103-111.

13. Sole-Smith V (2014) The history of autism. Parents Meredith Corporation.

14. Szatmari P (2003) The causes of Autism Spectrum Disorder. Bmj 326(7382): 173-174.

15. Developmental DMNSY \& 2010 Principal Investigators (2014) Prevalence of autism spectrum disorder among children aged 8 years-autism and developmental disabilities monitoring network, 11 sites, United States, 2010. Morbidity and mortality weekly report. Surveillance summaries (Washington, DC: 2002) 63(2): 1. 
16. Shen Y, Dies KA, Holm IA, Bridgemohan C, Sobeih MM, et al. (2010) Clinical genetic testing for patients with autism spectrum disorders. Pediatrics 125(4): e727-e735.

17. Folstein SE, Rosen-Sheidley B (2001) Genetics of autism: complex aetiology for a heterogeneous disorder. Nat Rev Genet 2(12): 943-955.

18. Gillberg C, Coleman M (2000) The biology of the autistic syndromes. Cambridge University Press.

19. Frith U, Happé F (2005) Autism Spectrum Disorder. Current biology 15(19): R786-R790.

20. McEvoy RE, Rogers SJ, Pennington BF (1993) Executive function and social communication deficits in young autistic children. J Child Psychol Psychiatry 34(4): 563-578.

21. Li J, Zhu L, Gummerum M (2014) The relationship between moral judgment and cooperation in children with high-functioning autism. Scientific reports 4.

22. Baron-Cohen S, Leslie AM, Frith U (1985) Does the autistic child have a "theory of mind"? Cognition 21(1): 37-46.

23. Ginsburg F, Rapp R (2013) Disability worlds. Annual Review of Anthropology 42: 53-68.

24. Crews DE, Zavotka S (2006) Aging, disability, and frailty: implications for universal design. Journal of physiological anthropology 25(1): 113-118.
25. Anthony JH (2010) Towards inclusion: influences of culture and internationalization on personhood, educational access, policy and provision for students with autism in Ghana. Doctoral dissertation, University of Sussex.

26. Nukunya GK (2003) Tradition and change in Ghana: An introduction to sociology. Ghana Universities Press.

27. Gray DE (1993) Perceptions of stigma: the parents of autistic children. Sociology of Health \& Illness 15(1): 102-120.

28. Wilcox CE, Washburn R, Patel V (2007) Seeking help for attention deficit hyperactivity disorder in developing countries: A study of parental explanatory models in Goa, India. Soc Sci Med 64: 1600-1610.

29. Bakare MO, Agomoh AO, Ebigbo PO, Eaton J, Okonkwo KO, et al. (2009) Etiological explanation, treatability and preventability of childhood autism: a survey of Nigerian healthcare workers' opinion. Annals of General Psychiatry 8(1): 6.

30. Fosu GB (1981) Disease classification in rural Ghana: Framework and implication for health behavior. Social Science and Medicine 15(4): 471482

31. Manu N (2012) Belief and Attitudes surrounding Childhood Autism in Ghana.

32. Ochs E, Solomon O (2010) Autistic sociality. Ethos 38(1): 69-92. 